Abstracta Iranica Abstracta Iranica

Revue bibliographique pour le domaine irano-aryen

Volume 27 | 2006

Comptes rendus des publications de 2004

Women in Iran from the Rise of Islam to 1800. University of Illinois Press, Urbana and Chicago, 2003, xiv-253 p., 12 fig., index, 10 contributions.

\title{
OpenEdition
}

Journals

Édition électronique

URL : http://journals.openedition.org/abstractairanica/5858

DOI : 10.4000/abstractairanica.5858

ISSN : 1961-960X

Éditeur :

CNRS (UMR 7528 Mondes iraniens et indiens), Éditions de l'IFRI

Édition imprimée

Date de publication : 15 mai 2006

ISSN : 0240-8910

Référence électronique

«Women in Iran from the Rise of Islam to 1800. University of Illinois Press, Urbana and Chicago, 2003, xiv-253 p., 12 fig., index, 10 contributions. », Abstracta Iranica [En ligne], Volume 27 | 2006, document 140, mis en ligne le 02 janvier 2007, consulté le 25 septembre 2020. URL : http://

journals.openedition.org/abstractairanica/5858 ; DOI : https://doi.org/10.4000/abstractairanica.5858

Ce document a été généré automatiquement le 25 septembre 2020.

Tous droits réservés 


\section{Women in Iran from the Rise of Islam to 1800. University of Illinois Press, Urbana and Chicago, 2003, xiv-253 p., 12 fig., index, 10 contributions.}

Premier volume d'un projet collectif sur l'histoire des femmes en Iran [le vol. II, voir c.r. $\mathrm{n}^{\circ} 215$ ] dirigé par deux spécialistes en histoire et en anthropologie. Ce livre s'ajoute avec bonheur à d'autres publications de ces dernières années consacrées aux aspects de l'histoire sociale et culturelle des femmes en Iran ou plus généralement dans le monde musulman (par ex. G. Hambley (éd.), Women in the Medieval Islamic World: Power, Patronage, and Piety, New York, St. Martin's Press 1998 ; voir Abs. Ir. 20-21, c.r. n43).

Après une chronologie et l'Introduction par G. Nashat, les 10 articles sont présentés selon l'ordre chronologique. L'éventail des sources mises à contribution pour chacun des articles est très large, allant des documents et chroniques historiques aux écrits littéraires, à l'iconographie..., émanant des milieux arabo-persans, mais aussi moyenperses, grecs, ou européens. Les articles portent un éclairage sur des aspects parmi d'autres, des milieux particuliers (principalement cependant les couches élevées de la société - approche déterminée par la nature des sources disponibles), des périodes spécifiques. Qu'elles évoluent dans les milieux de la cour, des élites urbanisées, ou au contraire qu'elles soient proches de la vie rurale et nomade, nous voyons les femmes dans l'exercice de leurs activités religieuses, jouant un rôle politique, agissant au niveau économique.

Le volume s'ouvre sur un essai général, également par G. Nashat, sur «Women in PreIslamic and Early Islamic Iran» (pp. 11-47), qui donne un aperçu sur la pérennité et l'évolution des normes sociales appliquées aux femmes dans la région "du Nil à Oxus", à partir de nombreuses sources. Deux articles s'attachent aux femmes urbaines vues à travers leurs activités religieuses et commerciales, à deux étapes différentes mais complémentaires de l'histoire iranienne : période "trouble" du lent et ambigu passage 
du zoroastrisme à l'islam (Jamsheed K. Choksy, «Women during the Transition from Sasanian to Early Islamic Times", pp.48-67), et période de grande stabilité et de prospérité économique juste avant les invasions mongoles (Richard W. Bulliet, "Women and the Urban Religious Elite in the Pre-Mongol Period », pp. 68-79).

4 Les femmes des élites en Iran n'étant pas toujours uniquement iraniennes, l'article de Julie Scott Meisami («Eleventh-Century Women: Evidence from Bayhaqi’s History », pp. 80-102), suivi de celui de Carole Hillenbrand ("Women in the Seljuq Period», pp.103-120), sont consacrés aux femmes évoluant dans les milieux princiers turcs d'origine centre-asiatique récente : d'un côté à la cour des Ghaznavides, et de l'autre, chez les princes seljuqides. Les deux articles s'intéressent particulièrement à la présence des femmes dans la sphère publique, et à la façon dont elles sont représentées et jugées dans les sources officielles telles que les chroniques historiques ou les écrits juridiques théoriques. Deux autres articles du volume poursuivent dans cette direction, tout en s'attachant à analyser l'apport de l'éducation et de l'indépendance financière dans les différentes manifestations de l'ingérence féminine dans la politique à l'époque timouride (Beatrice Forbes Manz, «Women in Timurid Dynastic Politics», pp. 121-139; cf. c.r. $n^{\circ} 152$ ) et safavide (Maria Szuppe, «Status, Knowledge, and Politics : Women in Sixteenth Century Safavid Iran », pp. 140-169; voir c.r. n¹94). Enfin, l'accent est mis sur la place des femmes à l'intérieur de la famille dynastique en tant que dépositaires d'une autorité royale, jouant ainsi un rôle déterminant dans le processus de légitimation pour ces dynasties d'origine turco-mongole et turkmène.

5 Les questions de légitimation sont approchées par un biais tout à fait différent dans l'article suivant par Mahmoud Omidsalar (« Waters and Women, Maidens and Might: The Passage of Royal Authority in the Shahnama», pp. 170-185). En se situant à la frontière entre l'histoire et la littérature, il offre en miroir une image historique et une image littéraire des femmes, car à partir des sources littéraires il touche au rôle des femmes en tant que transmettrices de la royauté. L'analyse d'œuvres littéraires persanes comme source principale d'inspiration pour l'identification de modèles féminins universels, mène Fatemeh Keshavarz (« Taming the Unruly King: Nizami's Shirin as Lover and Educator ", pp. 186-205) vers un article présentant une vision poétique et courtoise de la reine et de l'amante paradigmatique... Finalement, le volume se clôt sur une autre contribution générale, ici par Layla S. Diba, «Lifting the Veil from the Face of Depiction: The Representation of Women in Persian Painting " (pp. 206-236). Cet article passe en revue les diverses manières de représenter les femmes dans la peinture persane, depuis l'époque sassanide (seulement mentionnée) jusqu'au début du $20^{\mathrm{e}} \mathrm{s}$., en identifiant plusieurs catégories : héroïne littéraire ; idéal de beauté (amante, houri, représentation $\mathrm{du} \mathrm{nu}$ ); danseuse et musicienne; mère avec enfant, épouse, concubine...

6 L'ouvrage, édité avec grand soin grâce aux efforts conjugués des deux éditrices, se termine sur un index fort utile. Ce volume a reçu le prix annuel "Outstanding Academic Title 2003" décerné par Choice Magazine (publication de l'Association of College Research Libraries, American Library Association). 
INDEX

Thèmes : 4.0. Généralités 